\title{
Optimal design of a single-phase APF based on PQ theory
}

\author{
Dur Muhammad Soomro ${ }^{1}$, S. K. Alswed ${ }^{2}$, Mohd Noor bin Abdullah ${ }^{3}$, Nur Hanis binti Mohammad \\ Radzi $^{4}$, Mazhar Hussain Baloch ${ }^{5}$ \\ 1,2,3,4 Department of Electrical Power Engineering, FKEE, Universiti Tun Hussein Onn Malaysia, Malaysia \\ ${ }^{5}$ Department of Electrical Engineering, Mehran University Engineering SZAB Campus Khairpur, Pakistan
}

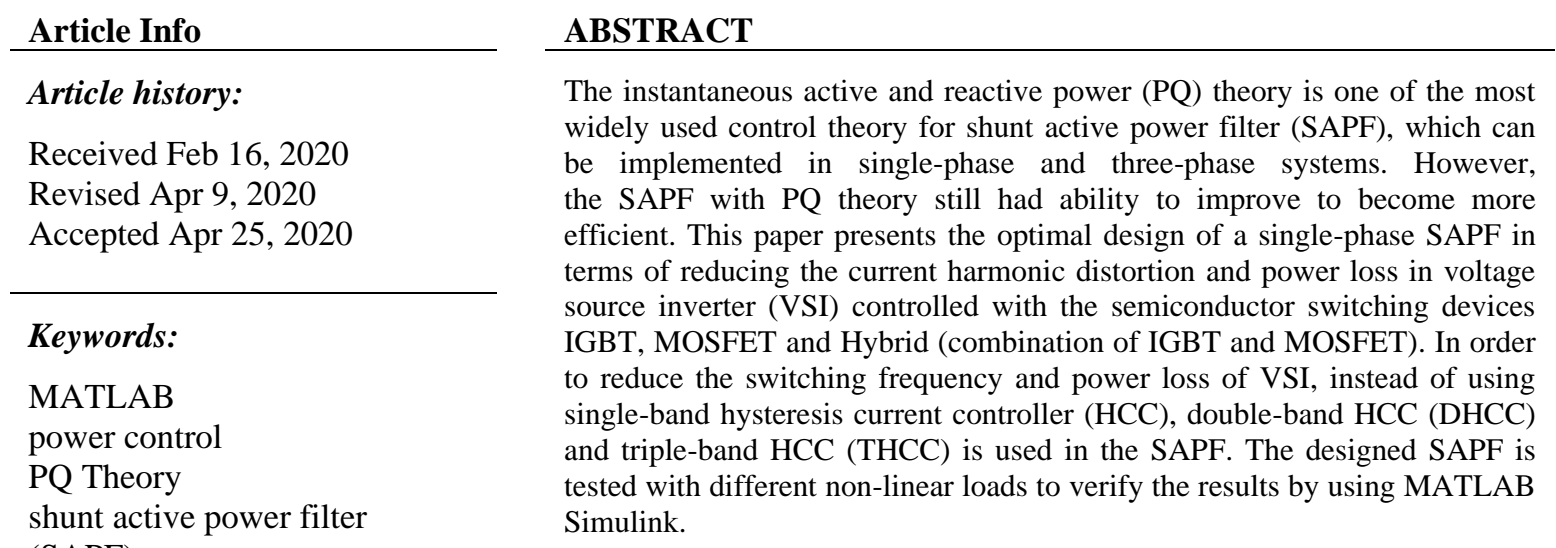

This is an open access article under the CC BY-SA license.

\section{Corresponding Author:}

Sager K. Alswed,

Department of Electrical Power Engineering,

Universiti Tun Hussein Onn Malaysia,

86400 Batu Pahat, Johor, Malaysia.

Email: ge140016@siswa.uthm.edu.my

\section{INTRODUCTION}

The increasing human population results in an increased demand for electricity. Since most of the electricity is generated by fossil fuel which is depleting day by day and causing air pollution. In order to overcome this crisis, energy efficiency equipment (EEE), electrical vehicles (EV) and renewable energy (RE) like solar and wind power are introduced. However, the mentioned solution is able to reduce the power consumption but will increase the harmonic in power system (PS) [1]. This is due to the EEE, the charging of $\mathrm{EV}$ and usage RE that requires the use of the semiconductor switching devices such as converters, which will drag the current to non-linearly form, thus causes harmonic injection in the PS. These loads are known as non-linear loads, which are the source of harmonic in PS.

The effect of harmonic will cause malfunction of sensitive electronic loads, malfunction of protection devices and power loss in the PS [2-3]. Therefore, people have more concern to improve PS quality. Among many other harmonic mitigation methods, SAPF is one of the most effective methods to deal with PS harmonic [4]. Besides harmonic compensation SAPF is also able to improve the power factor (PF), reduce the neutral current and unbalanced current condition.

Among other control theories for SAPF, the PQ theory is the most popular control theory used by the researchers [5]. This is due to the reason that PQ theory is able to give instantaneous harmonic compensation with fast response and applicable to single-phase as well as a three-phase system. Usually the PQ theory will pair with the HCC to give the fast response with a simple design. However, the normal HCC will produce high-frequency switching and will cause higher switching loss for the inverter. Therefore, 
in order to overcome the mentioned problem, DHCC and THCC are proposed [6]. Literature review shows that using DHCC and THCC able to reduce the switching frequency [7]. The advantages of reducing the switching frequency are able to reduce the switching stress and reduce the switching loss of the inverter.

This paper presents optimal design of single-phase SAPF with PQ theory, and the performance observed with HCC, DHCC and THCC for low voltage application by using MATLAB Simulink. To validate the proposed design of SAPF is tested on 5 types of non-linear loads. This paper also included the optimal design of SAPF in terms of the selection of the semiconductor switching devices for the VSI, dclink capacitor $\left(\mathrm{C}_{\mathrm{DC}}\right)$ and coupling inductor $\left(\mathrm{L}_{\mathrm{APF}}\right)$.

\section{RESEARCH METHODOLOGY}

\subsection{Deign of the filter}

There are various types of control theories that handle power filter applications [8]. However, for practical applications, power filter depends on more than just control theories but also design parameters values of $\mathrm{C}_{\mathrm{DC}}$ and $\mathrm{L}_{\text {apf. }}$. They play a significant role in ensuring successful operation of SAPF.

In this paper, SAPF topology is implemented to optimize and reduce current harmonics. The configuration of SAPF in PS is shown in Figure 1. The VSI is implemented in the SAPF and connected with a $\mathrm{C}_{\mathrm{DC}}$ to provide needed reactive power to compensate for current harmonics. Incorporated switching devices in VSI utilize semiconductors such as GTO [9], MOSFET [10] or IGBT [11], to provide switching pulses based on calculated harmonic compensation current ( $\mathrm{I}_{\text {comp }}$ ) according to control theory. The $\mathrm{L}_{\mathrm{APF}}$ is connected in series with SAPF to mitigate harmonics ripple effect by compensating reactive current. In the following detailed explanation of control theory, the determination of $\mathrm{C}_{\mathrm{DC}}$ and $\mathrm{L}_{\mathrm{APF}}$ values for VSI SAPF is provided.

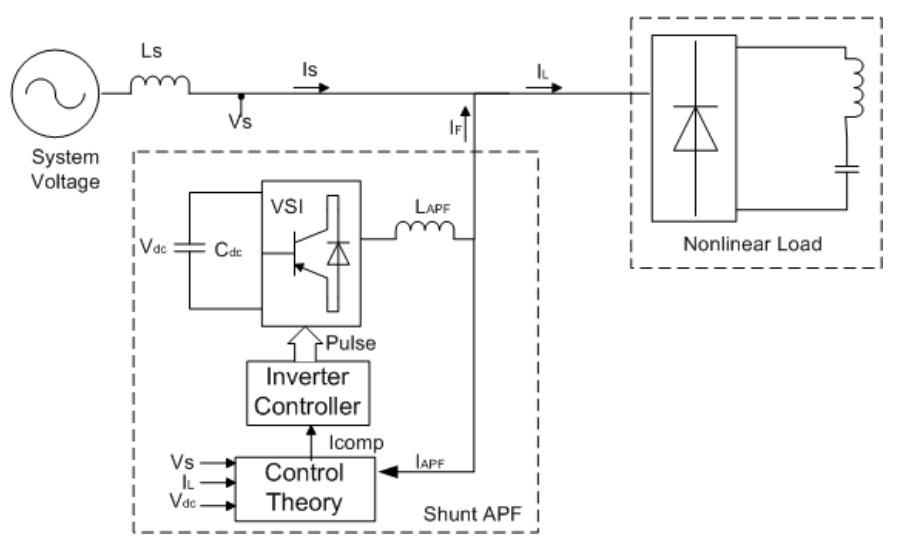

Figure 1. Connection of SAPF in PS

In order to verify the performance of the designed SAPF model, tested with different types of nonlinear loads were performed.

\subsection{Control theory - instantaneous active and reactive power (PQ) theory}

PQ theory was firstly introduced by Hirofumi Akagi to define instantaneous power for three-phase circuits in the time domain [12]. This control theory is modified to be applied in three-phase four wires system and single-phase system [13]. The calculation of the active power $(\mathrm{P})$ and reactive power $(\mathrm{Q})$ were based on instantaneous source voltage $\left(\mathrm{V}_{\mathrm{abc}}\right)$ and $\left(\mathrm{I}_{\mathrm{Labc}}\right)$ load current in three-phase PS [14]. Besides, it is also valid for steady-state or transient operation. Figure 2 shows the principal block diagram of the PQ theory. This control method is widely used due to its fast dynamic response against harmonics current compensation, system PF improvement, and unbalanced current loads conditions enhancement [15]. However, it requires an accurate and balanced sinusoidal source voltage. Therefore, for unbalanced and distorted source voltage condition a Unit Vector Template (UVT) addition is needed [16] or PLL with PQ theory.

In order to use the PQ theory for the single-phase system, firstly, it needs to transform single-phase supply voltage and non-linear load current from $V_{S}$ and $I_{L}$ to imaginary three-phase $V_{a b c}$ and $I_{\text {Labc }}$ form respectively. Both imaginary $v_{a b c}$ and $i_{L a b c}$ signals will be sent to Clarke's Transformation to transform from $a b c$ plane into $\alpha \beta 0$ coordinates as follows: 


$$
\begin{aligned}
& \left(\begin{array}{l}
v_{0} \\
v_{\alpha} \\
v_{\beta}
\end{array}\right)=\sqrt{\frac{2}{3}}\left(\begin{array}{ccc}
1 / \sqrt{2} & 1 / \sqrt{2} & 1 / \sqrt{2} \\
1 & -1 / 2 & -1 / 2 \\
0 & \sqrt{3} / 2 & -\sqrt{3} / 2
\end{array}\right)\left[\begin{array}{l}
v_{a} \\
v_{b} \\
v_{c}
\end{array}\right] \\
& \left(\begin{array}{l}
i_{0} \\
i_{\alpha} \\
i_{\beta}
\end{array}\right)=\sqrt{\frac{2}{3}}\left(\begin{array}{ccc}
1 / \sqrt{2} & 1 / \sqrt{2} & 1 / \sqrt{2} \\
1 & -1 / 2 & -1 / 2 \\
0 & \sqrt{3} / 2 & -\sqrt{3} / 2
\end{array}\right)\left[\begin{array}{l}
i_{L a} \\
i_{L b} \\
i_{L c}
\end{array}\right]
\end{aligned}
$$

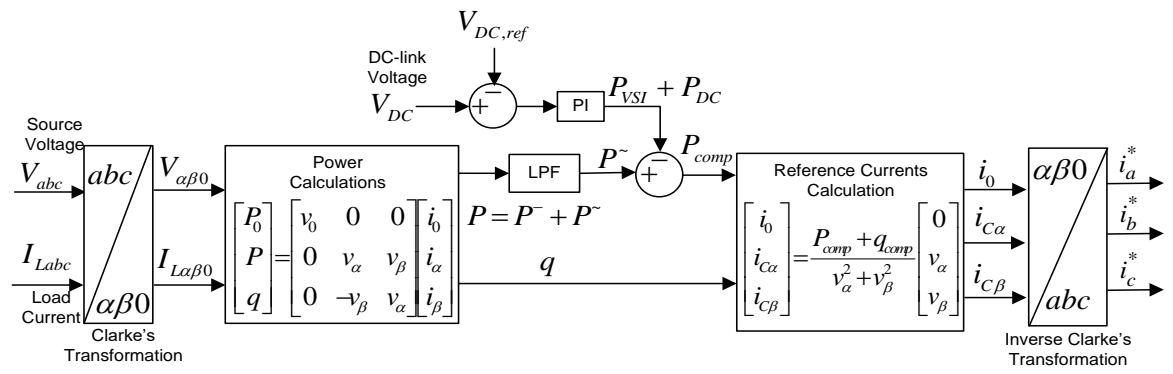

Figure 2. Principal block diagram of PQ theory

The PQ theory treats the three-phase system as a unit. The calculation of instantaneous $\mathrm{P}$ and $\mathrm{Q}$ is based on $\alpha \beta 0$-coordinates, voltages and currents. Calculated instantaneous power is defined as instantaneous zero sequence power $\left(P_{0}\right), \mathrm{P}$ and $\mathrm{Q}$. Besides, the calculated $P$ is the total active power of the system, including the power used by the load known as dc-component (fundamental component or active power, $\bar{P}$ ) and the ac-component (harmonic power, $\tilde{P}$ ). Therefore, it can be written as:

$$
P=\bar{P}+\tilde{P}
$$

The low pass filter (LPF) is used to filter out the $\tilde{P}$ to retain only the $\bar{P}$. This $\tilde{P}$ signal represents the harmonic power. The power loss in SAPF contain power loss in VSI $\left(P_{V S I}\right)$ and power loss in $\mathrm{C}_{\mathrm{DC}}\left(P_{D C}\right)$ which can be expressed as:

$$
P_{P F}=P_{V S I}+P_{D C}
$$

The $P_{V S I}$ value depends on the types of semiconductor switching devices and the switching frequency $\left(\mathrm{f}_{\mathrm{SW}}\right) . P_{V S I}$ was explained in detail previously in the "selection of the switching devices for the SAPF" section. The $P_{D C}$ can be obtained by using Proportional Integral (PI) controller as a result of the error between the reference voltage $\left(V_{D C, \text { ref }}\right)$ and the measured DC-link voltage $\left(V_{D C}\right)$ as shown in (10).

$P_{D C}=k_{P}\left(V_{D C, r e f}-V_{D C}\right)+k_{i} \int\left(V_{D C, r e f}-V_{D C}\right) d t$

Thus, the compensation power $\left(P_{\text {comp }}\right)$ for the SAPF can be calculated by:

$$
P_{\text {comp }}=\left(\bar{P}+P_{A P F}\right)-P=\left(P_{V S I}+P_{D C}\right) \tilde{P}
$$

The reactive power compensation $\left(q_{\text {comp }}\right)$ is equal to the calculated $\mathrm{Q}$. Thus, the $\alpha \beta$ compensation reference currents are:

$$
\left[\begin{array}{l}
i_{C a} \\
i_{C b}
\end{array}\right]=\frac{1}{v_{\alpha}^{2}+v_{\beta}^{2}}\left[\begin{array}{cc}
v_{\alpha} & v_{\beta} \\
v_{\beta} & -v_{\alpha}
\end{array}\right]\left[\begin{array}{l}
P_{\text {comp }} \\
q_{\text {comp }}
\end{array}\right]
$$

These compensation currents need to transform back to $a b c$ plane with Inverse Clarke's Transformation as (8) and (9): 


$$
\begin{aligned}
& {\left[\begin{array}{l}
i_{C a}^{*} \\
i_{c b}^{*} \\
i_{C c}^{*}
\end{array}\right]=\sqrt{2} / 3\left(\begin{array}{ccc}
1 / \sqrt{2} & 1 & 0 \\
1 / \sqrt{2} & -1 / 2 & \sqrt{3} / 2 \\
1 / \sqrt{2} & -1 / 2 & -\sqrt{3} / 2
\end{array}\right)\left(\begin{array}{c}
-i_{0} \\
i_{C \alpha} \\
i_{C \beta}
\end{array}\right)} \\
& i_{C a}^{*}=-\frac{1}{\sqrt{3}} i_{0}+i_{C \alpha}=-\frac{1}{\sqrt{3}} i_{0}+\frac{v_{\alpha} * P_{c o m p}+v_{\beta}^{*} q_{c o m p}}{v_{\alpha}^{2}+v_{\beta}^{2}}
\end{aligned}
$$

For single-phase system, only the $i_{C a}^{*}$ signal from (9) is used to generate the switching pulse for the APF inverter. $i_{C a}^{*}$ signal is sent to HCC in order to generate proper switching pulses for the APF power inverter.

\subsection{Hysteresis current controller}

Among many other current controller techniques to generate switching pulse [17], the HCC is the most extensively used for APF. This is because it is simple in design, fast response, easy to implement and possess unconditioned stability [18-20]. The principal operation of the HCC is to generate the switching pulse for VSI by comparing the real current (actual signal) and reference current (reference signal) within the hysteresis bands. The switching frequency of HCC depends on the charging current from the upper-band to lower-band; accordingly, the switching frequency will be varying.

The principal operation of the DHCC [21] is different from HCC. In terms of the switching, pulse is generated by comparing within the upper-band, lower-band and the reference current (reference signal) [22]. The switching of G1 and G2 pulses are generated for the changing of the actual signal within upper-band and reference signal, while G3 and G4 are generated for the changing of the actual signal within lower-band and reference signal. Therefore, the G1 and G4 will be switching ON off both switching pulses overlap and vice-versa for G2 and G3.

The principal operation of the THCC is similar to DHCC [23]. Only the difference is of switching pulse that is generated for G1 and G4 by comparing within the upper-band and $2^{\text {nd }}$ upper-band [24], where G2 and G3 by comparing within the lower-band and $2^{\text {nd }}$ lower-band [25].

\subsection{Determination of DC-link capacitor for SAPF}

The SAPF DC bus reference voltage, $\left(V_{\text {DCref }}\right)$ for single-phase and three-phase (three wires and four wires) system can be determined by using (10) and (11):

$$
\begin{aligned}
V_{D C, \text { min }} & \geq \frac{V_{S}}{\sqrt{2} m} \\
V_{D C, \text { max }} & \geq \frac{2 \sqrt{2} V_{S}}{\sqrt{3} m}
\end{aligned}
$$

Where

$V_{S}=$ Source voltage, $240 \mathrm{~V}$ for single-phase

$m=$ Amplitude modulation index (ratio of inverter DC-link voltage to system peak voltage)

The $m$ is considered as 1 because the inverter DC-link voltage had the same amplitude with the system peak voltage. Therefore, by using (10) and (11), the calculated values of $V_{D C, \min }$ and $V_{D C, \max }$ will be used to calculate the $\mathrm{C}_{\mathrm{DC}}$ by using the (12) for single-phase system.

$$
\frac{1}{2} C_{D C}\left[\left(V_{D C, \text { max }}\right)^{2}-\left(V_{D C, \text { min }}\right)^{2}\right]=V_{S}(a I) \frac{T}{2}
$$

Where

$a=$ Overloading factor

$I=$ Phase current supplied by the source to the load

$T=$ Time period of the system voltage $(0.02 \mathrm{~s})$

The $a$ is selected from its range of 120-180\% of steady-state current during the transient condition. It is selected with a value of 1.2 to 1.8 . After obtaining the $C_{D C}$ values, the selection of a capacitor must be closer and higher than the calculated value. For the SAPF design for 5 Amps current rating, the calculated $C_{D C}$ values are in a range of $220 \mu \mathrm{F}$ to $330 \mu \mathrm{F}$. In this paper, the chosen $C_{D C}$ value is $330 \mu \mathrm{F}$ at $180 \%$ overloading factor.

\subsection{Determination of coupling inductance for SAPF}

The selection of suitable series inductance values is crucial for the APF design, because it will affect the filtering ability and reducing the ripple for the compensated current [19]. In this paper, the inductance value is calculated based on the error analysis from the current ripple $\left(I_{r}\right) . I_{r}$ is defined as the difference 
between the compensate current and the reference current in pulse width modulation (PWM). For determining the maximum inductance value, firstly, we needed to find out the maximum current ripple $\left(\Delta I_{r}\right)$ and $\mathrm{f}_{\mathrm{sw}}$. These two values can be obtained from the $\mathrm{I}_{\mathrm{r}}$ and $\mathrm{T}_{\mathrm{s}}$ of the modulation signal with the current reference signal as shown in Figure 3.

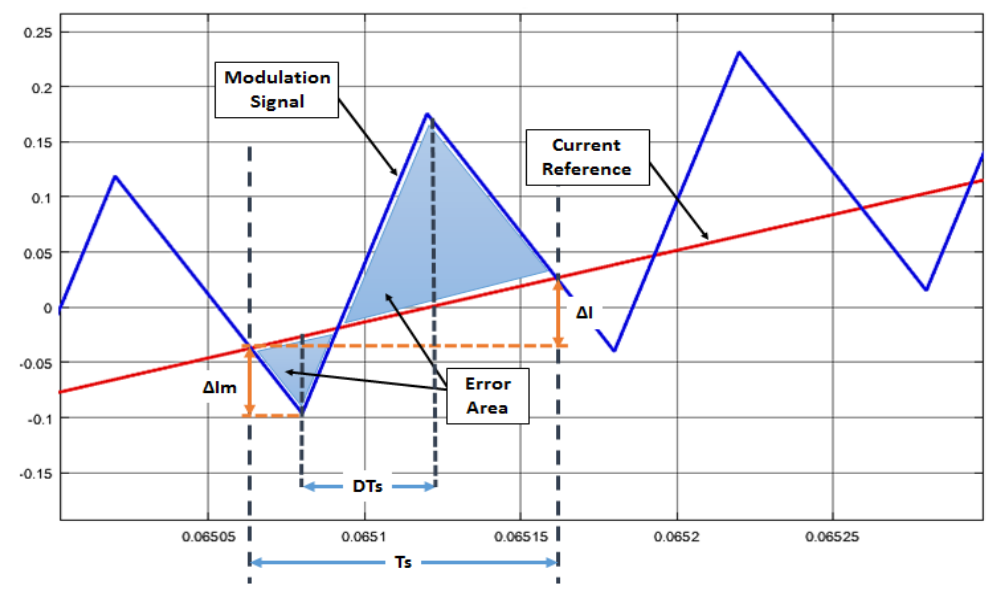

Figure 3. Current ripple of the modulation signal and current reference

From Figure 3, the collected value for $\Delta I_{m}$ and $\Delta I$ will be used to calculate the $\Delta I_{r}$ value with (13):

$$
I_{r}=\Delta I_{m}+\frac{(1-D)}{2} * \Delta I
$$

After obtaining the $\Delta I_{r}$ values, the $\mathrm{L}_{\mathrm{APF}}$ values can be selected from the calculated range of suitable inductance with (14):

$$
\frac{V_{S}-V_{D C, \min }}{\omega * I_{\max }} \leq L \leq \frac{V_{D C, \max }-V_{S}}{4 \Delta I_{r} * f_{S w}}
$$

Where

$$
\begin{aligned}
& \omega=2 \pi \mathrm{f}_{\mathrm{s}} \\
& I_{\text {max }}=\text { Maximum current } \\
& \Delta I_{r}=\text { Maximum current ripple } \\
& f_{S w}=\text { Switching frequency, } 10 \mathrm{kHz}
\end{aligned}
$$

For 5 Amps current rating single-phase SAPF, the calculated minimum inductance value is $40 \mathrm{mH}$ and the maximum inductance is $59.48 \mathrm{mH}$ (approximately to $60 \mathrm{mH}$ ). In order to find out the suitable inductance value for those SAPF with different switching devices, the calculated inductance values from 40

\begin{tabular}{|c|c|c|c|c|c|c|c|c|c|}
\hline \multirow{3}{*}{ Load } & \multicolumn{9}{|c|}{ Inductance value, $\mathrm{mH}$} \\
\hline & & IGBT & & & MOSFE & & & Hybrid & \\
\hline & $\mathrm{HCC}$ & DHCC & THCC & $\mathrm{HCC}$ & DHCC & THCC & $\mathrm{HCC}$ & DHCC & THCC \\
\hline L1 & 50 & 45 & 40 & 50 & 40 & 45 & 50 & 40 & 40 \\
\hline $\mathrm{L} 2$ & 55 & 40 & 40 & 50 & 40 & 45 & 50 & 45 & 45 \\
\hline L3 & 50 & 45 & 45 & 45 & 40 & 40 & 55 & 45 & 40 \\
\hline L4 & 40 & 40 & 40 & 50 & 45 & 40 & 50 & 45 & 45 \\
\hline Average $\mathrm{L}_{\mathrm{APF}}$ & 48.75 & 42.25 & 41.25 & 48.75 & 41.25 & 42.25 & 51.25 & 43.75 & 42.25 \\
\hline
\end{tabular}
$\mathrm{mH}$ to $60 \mathrm{mH}$ are tested with the non-linear loads along with $330 \mu \mathrm{F}$ capacitance. Table 1 shows the value of inductance which gives less THD for the non-linear loads with different switching devices VSI with HCC, DHCC and THCC. The selective values of inductance are based on the average inductance value. Therefore, simulation results of IGBT, MOSFET and Hybrid VSI based on $45 \mathrm{mH}$ are as shown in Table 1.

Table 1. The less THD inductance value for different VSI 


\section{RESULTS AND DISCUSSION}

The supply voltage is $240 \mathrm{~V}_{\mathrm{RMS}}\left(340 \mathrm{~V}_{\mathrm{p}}\right.$ and $\left.680 \mathrm{~V}_{\mathrm{pp}}\right)$. Therefore, it is expected that the $V_{D C}$ value will increase if the load current increases. The $V_{D C}$ will be swinging with a maximum voltage of $680 V_{D C, P P}$ and $480 V_{D C, R M S}$ values depending on the connected loads. Therefore, the selection of DC-bus reference voltage $\left(V_{D C, \text { ref }}\right)$ must be between the range of $340 \mathrm{~V}$ and $480 \mathrm{~V}$. For this $390 V_{D C \text {,ref }}$ value is selected for this paper. Figure 4 shows the simulation results of source current THD before and after connecting the designed SAPF with different VSI (IGBT, MOSFET and Hybrid).

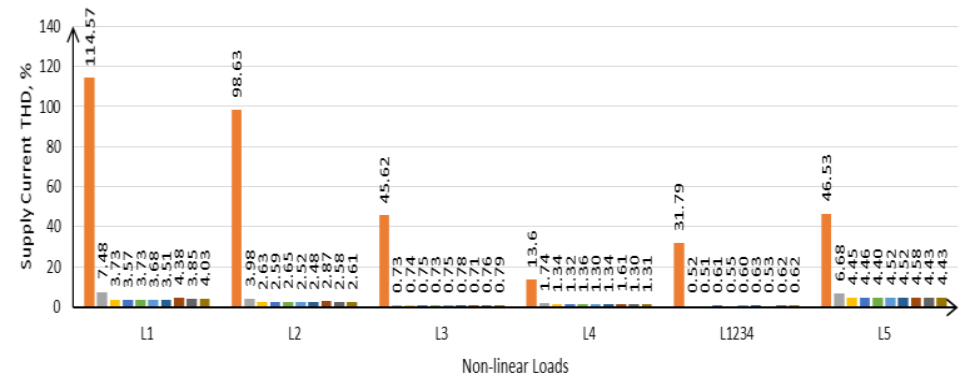

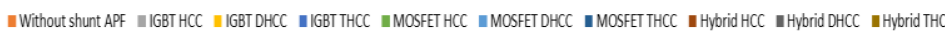

Figure 4. Source current THD before and after SAPF

Figure 5 shows the source current THD with the harmonic limit of IEEE-519 standard (\%THD $\leq 5$ $\%$ ). From this, we can observe that the designed SAPF with $\mathrm{HCC}$ is working well for $3.73 \%$ to $0.52 \%$, but with the excess harmonic limit of L5 as estimated. This is due to the L5 had a higher current rating. With HCC only the VSI IGBT possess higher current THD for L1, L2 and L5, as expected, since IGBT produces higher compensate harmonics than MOSFET. TheVSI $I_{M O S F E T}$ and VSI $I_{\text {HYBRID }}$ had similar performance with HCC, DHCC and THCC as estimated. The VSI of MOSFET overall gives reasonable harmonic compensation along with HCC, DHCC and THCC compared to VSI of IGBT VSI. The VSI for the Hybrid DHCC and THCC do not show the significant improvement in current THD for $3.73 \%$ to $0.56 \%$, but it is able to reduce the current THD below the standard limit for $4.43 \%$. This proves the concept of a theory that the combination of IGBT and MOSFET (Hybrid VSI) is able to give better harmonic compensation for low current rating applications.

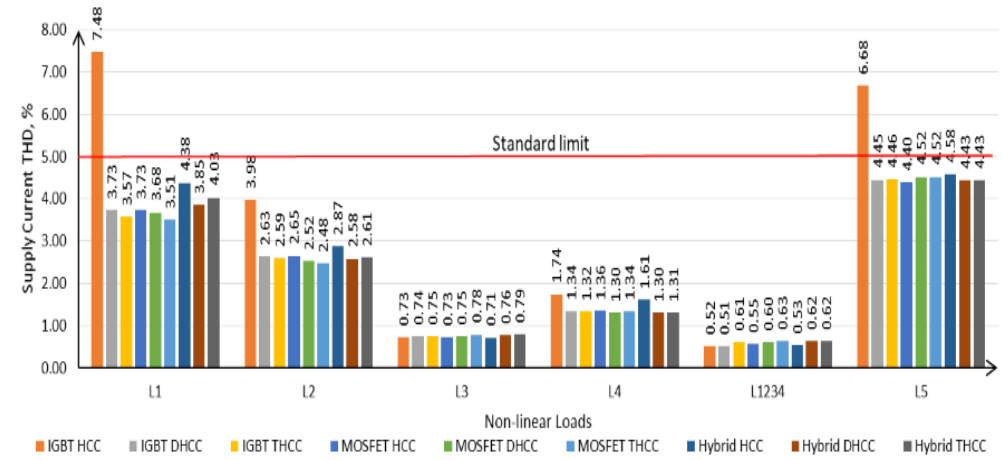

Figure 5. Source current THD after SAPF with the standard limit

Figure 6 shows the collected average switching frequency for HCC, DHCC and THCC. Table 2 shows the reduction of switching frequency of DHCC and THCC over HCC. From the collected results, we can see that the DHCC and THCC reduce the switching frequency significantly for L1 to L4 and L5. For L1234 it is less significant due to the standard limit. For this load the SAPF needs to compensate both even and triple-harmonic. The switching frequency of DHCC and THCC can reduce more, if the setting for the hysteresis band is more significant, as a result of $\mathrm{THD}_{\mathrm{I}}$ increasing. This is due to lower the switching frequency, the compensate current becames less than the real current signal and causes the THD $_{\text {I }}$ to increase. 


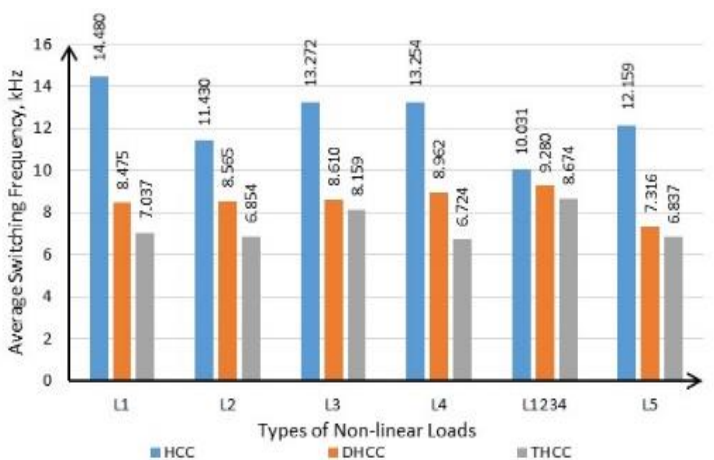

Figure 6. Collected average switching frequency for $\mathrm{HCC}$, DHCC and THCC
Table 2. Reduction of switching frequency in

\begin{tabular}{ccc} 
DHCC and THCC over HCC \\
\hline \multirow{2}{*}{ Load } & \multicolumn{2}{c}{ Reduction of SW, \% } \\
& DHCC & THCC \\
\hline L1 & 41.471 & 51.402 \\
L2 & 25.066 & 40.035 \\
L3 & 35.127 & 38.525 \\
L4 & 32.383 & 49.268 \\
L1, L2, L3, L4 & 7.487 & 13.528 \\
L5 & 39.831 & 43.770 \\
Average & 36.273 & 47.306 \\
\hline
\end{tabular}

Since, the HCC had varaible switching frequency, the collected average frequency shown in Figure 6 is used to calculate the power loss of the respectively simulated VSI which is shown in Figure 7. For L1 to L1234, low current, the HCC produce high switching frequency so the $V S I_{I G B T}$ had more power losses due to switching loss. However, when current increases, VSI MOSFET had high conduction loss and causing higher power loss and increasing the $V S I_{I G B T}$ at L5. While the $V S I_{H Y B R I D}$ show less significant reducion in power loss compared to $V S I_{I G B T}$ and $V S I_{H Y B R I D}$. While the higher load current of L5 it shows less power loss than $V S I_{M O S F E T}$ and $V S I_{I G B T}$. However, applying DHCC and THCC for $V S I_{I G B T}$, significantly reduce the power loss for $V S I_{I G B T}$. This is because the primary power loss in IGBT is switching loss. VSI $I_{\text {HYBRID }}$ DHCC and $V S I_{\text {HYBRID }}$ THCC t show less power loss compared to $V S I_{\text {MOSFET }}$ DHCC and $V S I_{M O S F E T}$ THCC hen the current increases for L5. This proves the theoretical assumtion that the VSI HYBRID will be able to serve the advantages of both IGBT and MOSFET by providing a low power loss of VSI and better harmonic compensation for low switching frequency at higher current rating applications.

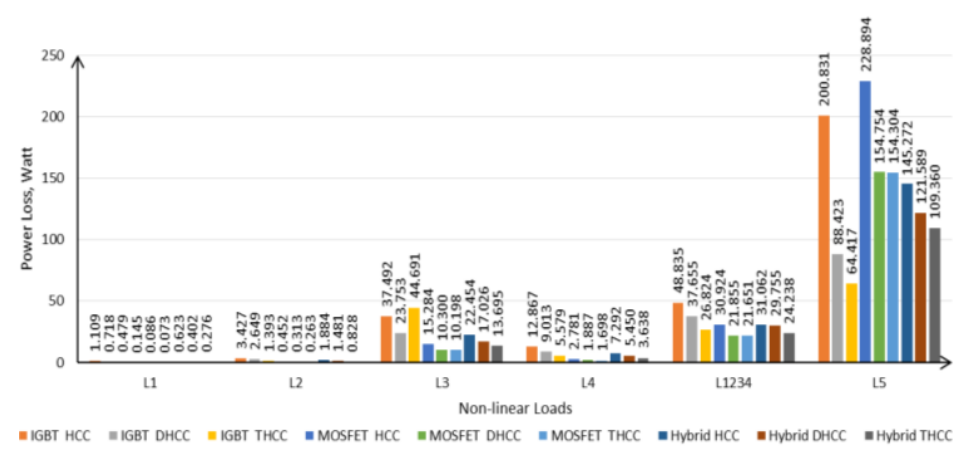

Figure 7. Calculated power loss in VSI with non-linear loads

\section{CONCLUSION}

In this paper, the performance of SAPF based on PQ theory with different types of $V S I_{H C C}, V S I_{D H C C}$ and $V S I_{T H C C}$ current controllers are investigated. Simulation results show that at the proper selective of coupling inductance, the switching devices will be able to improve the capability of harmonic compensation. From the simulation results, it also can be concluded that the $V S I_{M O S F E T}$ and $V S I_{H Y B R I D}$ give similar and better harmonic compensation compared to $V S I_{I G B T}$ when the current is increased. However, the performance of $V S I_{I G B T}$ is improved along with DHCC and THCC, as well as provided fewer power losses compared to others. Therefore, by using DHCC and THCC for VSI, it not only just reduces the power loss, but also improve the SAPF capability for using the L5 that has a higher current rating than the designed current rating (5 Amps). The $T H D_{i D H C C}, T H D_{i T H C C}$ or all types of switching devices of voltage inverter are below the IEEE-519 standard harmonic limit. The DHCC and THCC are able to reduce the switching frequency at an average of $35 \%$ and $45 \%$ respectively over the HCC. So, the simulation' results proved the usage of DHCC and THCC and are able to improve the SAPF performance for the rating of 3 times 
higher current loads. This can conclude that, the $V S I_{I G B T}$ THCC is the best combination of VSI, because it provides the least power loss and proper harmonic compensation ( $\mathrm{THD}_{\mathrm{I}}$ less than $5 \%$ ). In this paper the power loss of SAPF is estimated with the collected average switching frequency. This is because of the fixed PI voltage controller which is used for regulating the DC-link voltage

\section{REFERENCES}

[1] M. Pourbehzadi, T. Niknam, J. Aghaei, G. Mokryani, M. Shafie-khah, and J. P. Catalão, "Optimal operation of hybrid AC/DC microgrids under uncertainty of renewable energy resources: A comprehensive review," International Journal of Electrical Power \& Energy Systems, vol. 109, pp. 139-159, 2019.

[2] H. Molder, et al, "Harmonic losses in induction motors caused by voltage waveform distortions," in Proceedings of the 2010 Electric Power Quality and Supply Reliability Conference, pp. 143-150, 2010.

[3] G. Singh, "Power system harmonics research: a survey," European Transactions on Electrical Power, vol. 19, no. 2, pp. 151-172, 2009.

[4] S. Samal and P. K. Hota, "Wind Energy Fed UPQC System for Power Quality Improvement," Bulletin of Electrical Engineering and Informatics (BEEI), vol. 7, no. 3, pp. 495-504, 2018.

[5] R. Kumar and H. O. Bansal, "Shunt active power filter: Current status of control techniques and its integration to renewable energy sources," Sustainable Cities and Society, vol. 42, pp. 574-592, 2018.

[6] H. Komurcugil, "Double-band hysteresis current-controlled single-phase shunt active filter for switching frequency mitigation," International Journal of Electrical Power \& Energy Systems (IJPEDS), vol. 69, pp. 131-140, 2015.

[7] N. Kumar, T. K. Saha, and J. Dey, "Design and analysis of a double band hysteresis SMC for cascaded inverterbased PV system," in 2016 IEEE Region 10 Conference (TENCON), pp. 898-902, 2016.

[8] L. SARIBULUT, A. TEKE, M. Meral, and M. Tumay, "Active power filter: review of converter topologies and control strategies," Gazi university journal of science, vol. 24, no. 2, pp. 283-289, 2011.

[9] A. Anthon, et al, "Comparison of a state-of-the-art Si IGBT and next generation fast switching devices in a $4 \mathrm{~kW}$ boost converter," in 2015 IEEE Energy Conversion Congress and Exposition (ECCE), pp. 3003-3011, 2015.

[10] L. Zhao, H. Li, Y. Liu, and Z. Li, "High efficiency variable-frequency full-bridge converter with a load adaptive control method based on the loss model," Energies, vol. 8, no. 4, pp. 2647-2673, 2015.

[11] E. Romero-Cadaval, V. Miñambres-Marcos, and M.-I. Milanés-Montero, "Analysis and optimization of sinusoidal Voltage Source Inverter losses for variable output power applications," in 2011 7th International ConferenceWorkshop Compatibility and Power Electronics (CPE), pp. 230-235, 2011.

[12] H. Akagi, "New trends in active filters for power conditioning," IEEE transactions on industry applications, vol. 32, no. 6, pp. 1312-1322, 1996.

[13] J. Mindykowski, X. Xiaoyan, and T. Tarasiuk, "A new concept of harmonic current detection for shunt active power filters control," Measurement, vol. 46, no. 10, pp. 4334-4341, 2013.

[14] A. Nabae, "An instantaneous distortion current compensator without any coordinate transformation," IEEJ IPECYokohama'95, vol. 1651, 1995.

[15] J. Pinto, B. Exposto, V. Monteiro, L. F. Monteiro, C. Couto, and J. L. Afonso, "Comparison of current-source and voltage-source Shunt Active Power Filters for harmonic compensation and reactive power control," in IECON 2012-38th Annual Conference on IEEE Industrial Electronics Society, pp. 5161-5166, 2012.

[16] T. Santos, J. Pinto, P. Neves, D. Gonçalves, and J. L. Afonso, "Comparison of three control theories for singlephase active power filters," in 2009 35th Annual Conference of IEEE Industrial Electronics, pp. 3637-3642, 2009.

[17] S. Buso, L. Malesani, and P. Mattavelli, "Comparison of current control techniques for active filter applications," IEEE transactions on industrial electronics, vol. 45, no. 5, pp. 722-729, 1998.

[18] N.-Y. Dai and M.-C. Wong, "Design considerations of coupling inductance for active power filters," in 2011 6th IEEE Conference on Industrial Electronics and Applications, pp. 1370-1375, 2011.

[19] S. Gareh, B. Kok, M. Yee, A. A. Borhana, and S. Alswed, "Optimization of the Compression-Based Piezoelectric Traffic Model (CPTM) for Road Energy Harvesting Application," International Journal of Renewable Energy Research (IJRER), vol. 9, no. 3, pp. 1272-1282, 2019.

[20] S. Jena, B. Mohapatra, and C. K. Panigrahi, "Realization of double band hysteresis current controller for single phase grid connected pulse width modulated voltage source inverter," in 2015 International Conference on Man and Machine Interfacing (MAMI), pp. 1-6, 2015.

[21] P. C. Loh, et al, "A time-based double-band hysteresis current regulation strategy for single-phase multilevel inverters," IEEE Transactions on Industry Applications, vol. 39, no. 3, pp. 883-892, 2003.

[22] Z. Chelli, R. Toufouti, A. Omeiri, and S. Saad, "Hysteresis control for shunt active power filter under unbalanced three-phase load conditions," Journal of Electrical and computer Engineering, vol. 2015, 2015.

[23] O. Varaprasad and D. S. Sarma, "An improved three level Hysteresis Current Controller for single phase shunt active power filter," in 2014 IEEE 6th India International Conference on Power Electronics (IICPE), pp. 1-5, 2014.

[24] S. K. Ram and B. B. Das, "Comparison of different control strategy of conventional and digital controller for active power line conditioner (APLC) for harmonic compensation," in 2013 12th International Conference on Environment and Electrical Engineering, pp. 209-214, 2013.

[25] N. M. B. Sham, et al, "i-Capacitor Voltage Control for PV Z-source System with Enhanced Shoot-through," International Journal of Power Electronics and Drive Systems (IJPEDS), vol. 9, no. 4, pp. 1899-1911, 2018. 